Christensen, R., Greenhalgh, S., and Thomassen, A. (2019). "When a business case is not enough, motivation to work with lean." In: Proc. $27^{\text {th }}$ Annual Conference of the International. Group for Lean Construction (IGLC), Dublin, Ireland pp. 275-286. DOI: https://doi.org/10.24928/2019/0146. Available at: <www.iglc.net>.

\title{
WHEN A BUSINESS CASE IS NOT ENOUGH MOTIVATION TO WORK WITH LEAN
}

\author{
Randi Christensen ${ }^{1}$, Stephen Greenhalgh ${ }^{2} \&$ Anja Thomassen ${ }^{3}$
}

\begin{abstract}
Lean practitioners have always been very passionate about sharing their experiences and knowledge so others also can benefit from better processes and reduced waste. When lean practitioners get together to discuss and spread knowledge, the 'implementation of lean' is often at the core of the conversation. How do we get others to understand the nature of lean and how do we get them to implement it? Despite clearly documented, positive outcomes and strong business cases, we still encounter resistance and it can be challenging to even get our own colleagues to be engaged with lean.

This paper explores what motivates individuals with different project roles to work with lean, when some research shows that knowledge and will is not enough to change. It considers why incentive measures and a focus on time and cost savings could have a negative impact on the motivation to change for some groups. This discussion is supported with survey data and experiences from a major infrastructure project and within the organisation of the client, Highways England.
\end{abstract}

\section{KEYWORDS}

Lean construction, implementation, motivation, sense making, change

\section{INTRODUCTION}

No one ever said: "When I lack motivation to go to work in the morning, I just remember that my team contribute to cost and time savings. By constantly optimising our own work processes I know we contribute to significant savings every day, which is documented in important trackers, spreadsheets and in case examples. This motivates me to do my best!'. (Inspired by Münster, 2017).

Implementing lean construction from the lean construction community's perspective is seen as a significant change from traditional project management and perhaps even a paradigm shift (Korb \& Ballard 2018). By lean practitioners it is seen as a fundamental

1 PhD, MSc, Lean Manager, COWI working on behalf of Highways England at Lower Thames Crossing, London, Co-Founder of CollabDecisions, +44 7702 856113, rmch@cowi.com

2 BSc, Civil Engineering, Lean Manager for East Region \& Complex Infrastructure Programme for Highways England stephen.greenhalgh@ @ighwaysengland.co.uk

$3 \mathrm{PhD}$, Cand.merch Anja O. Thomassen, Associate Professor, Department of Learning and Philosophy, Aalborg University, aot@ learning.aau.dk 
shift from construction's traditional transformation processes to a more production line methodology and a systematic approach to management and continual improvement. Lean practitioners recognise that they need to support project production with a different approach and a different skill set. The lean community also seems to see a fundamental need to understand this paradigm shift in theory before practice (Howell and Koskela 2000).

As a lean practitioner, when you have recognised this shift, it can be highly challenging to work with non-lean practitioners. You ask yourself, "Why can't they see they are wrong?", "Why can't they see that lean is much more beneficial?". This is often the point where lean practitioners start looking for hard evidence of the outcomes of a lean approach. The frustrations then surface when this information does not have an impact on non-lean practitioners. It can result in lean practitioners feeling a sense of resignation when the clear evidence of the impact of lean construction is ignored or disbelieved (Korb \& Ballard 2018). The mentality of people seems to be the root problem for change (Koskela et al 2003).

In this paper, we explore how best to implement lean construction by considering what motivates project team members to work with lean construction and continual improvement. More knowledge about motivating factors might support future research to explore how to most efficiently implement lean construction. Thus, the research question is: "What motivates and demotivates people to work with lean and is motivation influenced by role, discipline and hierarchical position?".

\section{STRUCTURE AND METHOdOLOGY}

Firstly, we will discuss what research and literature tell us about motivation for change and sense making, and how this can be impacted by different factors in the specific context. Secondly, the theoretical discussion is supplemented by observations carried out on a specific case, the Lower Thames Crossing scheme. A lean specialist working for Highways England, a large infrastructure client and operator in UK and the lean manager working on the specific case recorded their observations using the client's standard approach. The client had developed its approach to standardise the assessment of lean activity, strategy and culture across all of its significant infrastructure projects. We also provide an insight of how the client has set up and motivated its supply chain to adopt a lean construction approach. The observations are supported by findings from a survey sent to the full-time staff on the project asking questions on lean implementation and the motivation to work with lean.

A questionnaire was developed which consisted of 22 questions, including 6 that were focused on motivation. The questionnaire was sent to 260 recipients across the project organisation, of which 167 were fully or partly completed, giving a response rate of $60 \%$. This response rate is considered as acceptable. The intention of sending the questionnaire to all relevant organisational levels was to provide a diverse range of opinions. However, as the number of respondents at each level was limited, this influenced the survey's explanation power. This is taken into account in this research, as the answers are perceived as indicators and not as objective facts (Bryman 2015; De Vaus 2013). 
The collaboration between the lean manager, who works full time on the project, and the client lean specialist, who visits the project approximately once a month, have ensured the reflection on practice, and an external researcher have provided critical input to the research methods and results.

\section{WHEN DOES CHANGE MAKE SENSE?}

Management literature has previously focused on how to create change and behaviour by using a few logical steps. Firstly, we need to ensure the employees have the right knowledge and secondly, we need to ensure that the receiver is convinced and wants to change. If the receiver gets the right information and understands the benefit of the change, they will start changing. (Münster 2017)

With his book "Thinking Fast Thinking Slow", Daniel Kahneman influenced a new generation of management literature, to understand that people do not act as they do due to deliberate considerations but out of habits. Two systems were proposed; System 1 is our automatic pilot that takes us through the day where thousands of decisions are taken with little effort. System 2, on the other hand, supports more deliberate changes, but this is a very resource heavy thought process and our capacity is to implement these changes is limited. Therefore, when we are under pressure, changes are unlikely to happen through these deliberate processes (Kahneman 2011). Therefore, we need to consider how to influence the more unconscious thought processes to change behaviour.

Motivation can also be divided up into intrinsic and extrinsic motivation. Intrinsic motivation refers to doing something because it is interesting or enjoyable, whereas extrinsic motivation refers to doing something because it leads to something else (Ryan and Deci 2000). For example, performance and incentivisation measures can be considered an extrinsic motivation for the project team. Extrinsic motivation leads to higher performance when the work tasks are simple and require a large portion of System 1 thinking (Pink 2007). This can be applied to refining known processes and making them more efficient and reliable. But, if the processes by which you reach your goal are unknown or highly complex, incentives have been shown to have a negative impact on performance. In other words, extrinsic motivation factors seem to undermine System 2 thinking. This is worth considering when motivating to use lean construction in highly complex work environments where creativity and problem solving form a large part of the work.

The elements that build intrinsic motivation are things like autonomy, mastery and purpose (Pink, 2007). Autonomy might include the ability to set up your own team, to manage your own time and define tasks. Mastery is the ability to develop skills and purpose to achieve something meaningful and important. A lack of motivation is the result from not valuing activity, not feeling competent to do it or not believing it will lead to a desired outcome (Ryan and Deci 2000).

In addition to motivation, Weick's notion of sense making might be helpful in understanding why people continue to behave in similar ways despite obvious facts support a change in behaviour. Weick's argument is that people implement new methods and processes if it makes real sense to the individual. For example, a project manager might tell you that it is a good idea to implement lean; however, if this does not make sense to you, it will not influence a change in behaviour. If it is received as an instruction and 
thereby a limitation of autonomy, it might even inhibit change. Hence, change does not occur due to good arguments and convincing results, change occurs when it makes sense to change (Weick 1995).

\section{LEAN IMPLEMENTATION ON A MAJOR INFRASTRUCTURE PROGRAM}

Lower Thames Crossing is a £5bn infrastructure project for Highways England, the government organisation responsible for the strategic road network in England. The project will connect the highway network from North East to South East of London with some 20 $\mathrm{km}$ of roads and what will be the world 3rd biggest tunnel of its kind under the River Thames. The project is scheduled to open in 2027 and is currently in the preliminary design phase.

\section{Client Demand AND EXPECTATIONS}

Since the mid-2000s, Highways England has been influencing its supply chain to adopt a lean approach to construction and from 2011 has used lean maturity to determine which suppliers the company wants to continue to do business with (Drysdale, 2013). Highways England state that the more mature a company is in adopting a lean approach, the better understanding it has of lean which leads to delivery of improvements in cost, time and quality and creates a more globally competitive supply chain. Highways England developed a lean maturity assessment tool (HELMA) to encourage its "supply chain to adopt lean principles to help foster a culture of continuous improvement for mutual advantage." They suggest that the outcome of the HELMA can help organisations highlight areas for improvement, with suppliers encouraged to implement an improvement action plan to drive lean deployment across their organisation.

Once in a contractual relationship the requirements of Highways England's suppliers become more explicit. Contracts include clauses such as the use of continual improvement, based upon lean principles to generate and realise reductions in the costs. A requirement of Highways England's funding from government is that design, construction and maintenance of its network should be more efficient, hence why it also expects its supply chain to deliver and document efficiencies based on a lean approach (Highways England 2015, HM Government 2015). Efficiencies have to be documented showing a saving in either time and/or cost, or a documented delivery of value beyond expected. There is a requirement for regular forecasts and reports on progress on delivering and documenting efficiencies in relation to a specific target set by Highways England for each scheme.

These measures are expected to incentivise the its supply chain to continual deliver more value with either the same or fewer resources. Highways England also provides support to both implement lean and deliver efficiencies with its specialists, to some extent, actively engaging with projects to ensure a continual development and focus on lean and the delivery of efficiencies. Highways England also facilitate knowledge transfer through the sharing of efficiency registers, peer-to-peer lean practitioner events and smaller lessons learned meetings. 


\section{LEAN STRATEGY AND DEPLOYMENT PLAN}

On the Lower Thames Crossing scheme, a Lean Strategy and Deployment Plan sets out the requirements for continual improvement and developing competencies within lean construction on the project. Furthermore, the team is responsible for delivering and documenting efficiencies, and to deliver value management and innovations. Initially the Lean Strategy and Deployment Plan was based on the requirements and incentivisation measures set by the client, Highways England. Although the strategy has been stable, the deployment plan has been updated due to:

- Changes in the scheme stages and meeting specific challenges;

- Development in project lean maturity, and;

- Resource constraints.

The changes of the deployment plan have been made in collaboration between the lean manager and client specialist lead. The lean implementation for the current stage of the project is centred around four main initiatives: Last Planner System (Collaborative Planning), Choosing by Advantages (Further described in (Schöttle et al 2018)), Visual Management and a Lean Training Program. A team of lean champions and Choosing by Advantages facilitators have been trained to support the lean implementation.

\section{LEAN RESULTS}

In addition to lean maturity assessments of the organisations delivering the scheme, the lean maturity of the project has been assessed four times since its commencement. The lean maturity (on a scale of 0 to 4) has increased from a level 1.5 in February 2017 to a level of 2.05 in November 2018. Furthermore, the project has delivered more than $300 \%$ of the required efficiencies for the current financial period, although none of these have been explicitly linked with lean initiatives.

\section{LEAN AWARENESS SURVEY}

In order to understand the breadth of lean understanding on the scheme, a lean survey of the project team was undertaken in November 2018. The respondents covered a wide range of project staff from project senior leaders to graduates, see Figure 1. As the project is in the preliminary design phase, the project team has a significant proportion of technical specialists and engineers contributing to the design. 


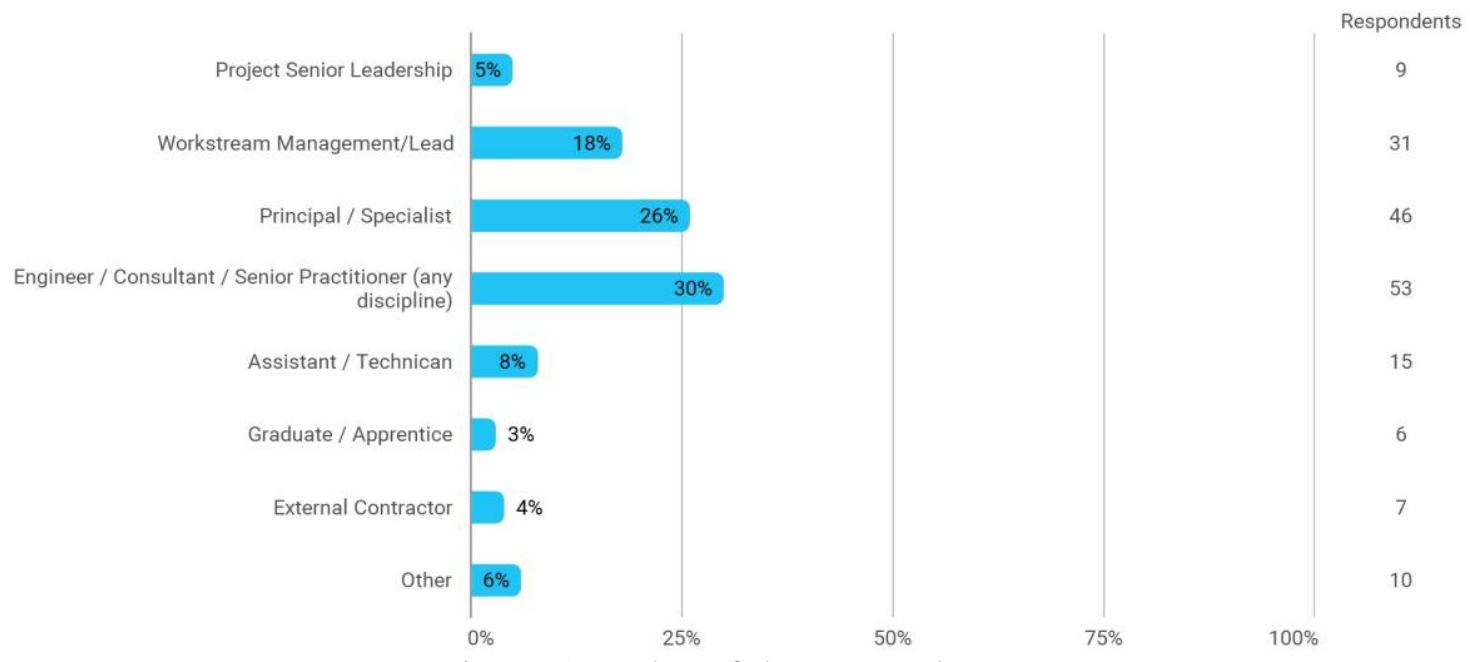

Figure 1: Roles of the respondents

As lean has been part of the scheme management approach for more than 2.5 years, the team is expected to have knowledge about lean practices and tools. Some $63 \%$ responded they understood the concept of lean and on a scale from 0-100 the respondents rated their average knowledge to 33 . Around $41 \%$ responded to having had some kind of lean training (from 3 hours to 10 weeks programme). Over $60 \%$ responded that they believed lean could be further developed in their role, see Figure 2. In summary the majority of staff had an understanding of lean and it would appear that there is a positive attitude towards lean in the Lower Thames Crossing team.
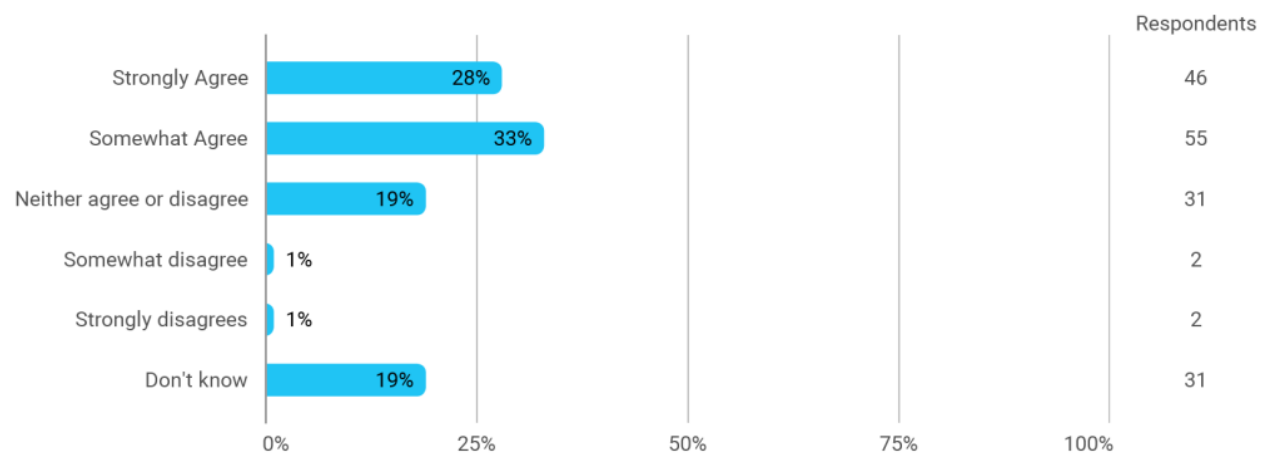

Figure 2: Responses to the question: Can Lean be further implemented in your role?

When asking what motivates the project team to work with lean, $32 \%$ responded that they were motivated by the ability to improve their own personal work processes, $22 \%$ by contributing to better quality and $15 \%$ to savings and time reductions, see Figure 3. 

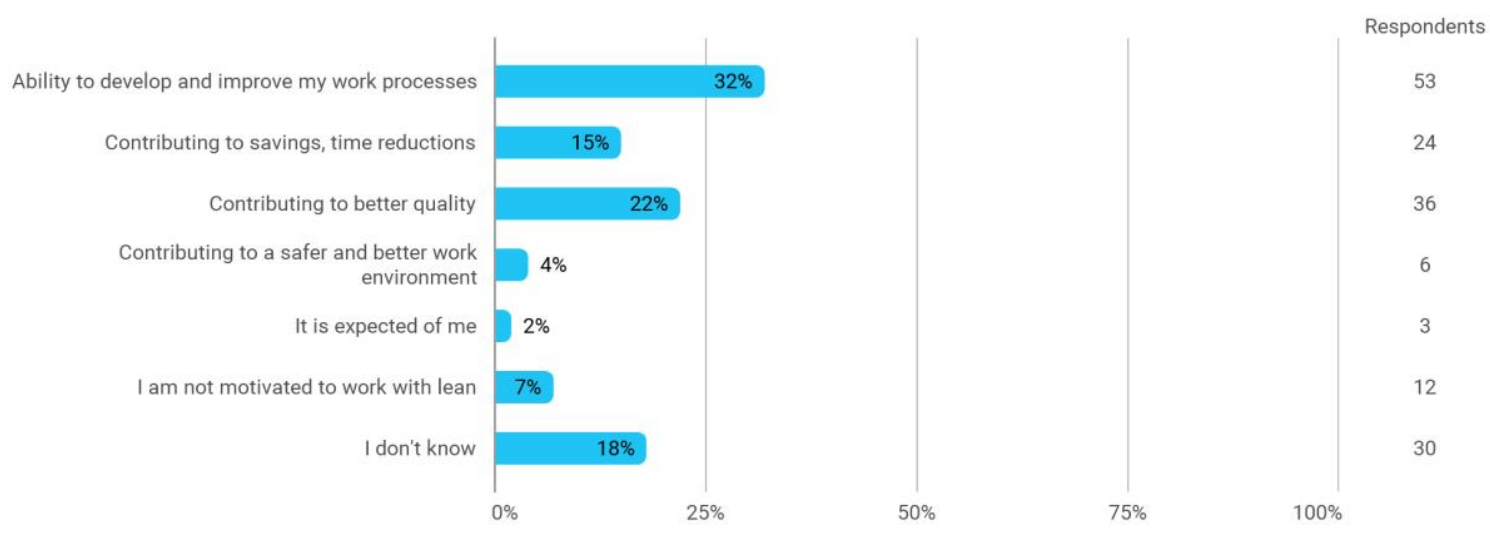

Figure 3: Responses to the question: What motivates you most to work with Lean?

Diving down in the results to see what motivates the different roles gives slightly different picture, see Figure 4.

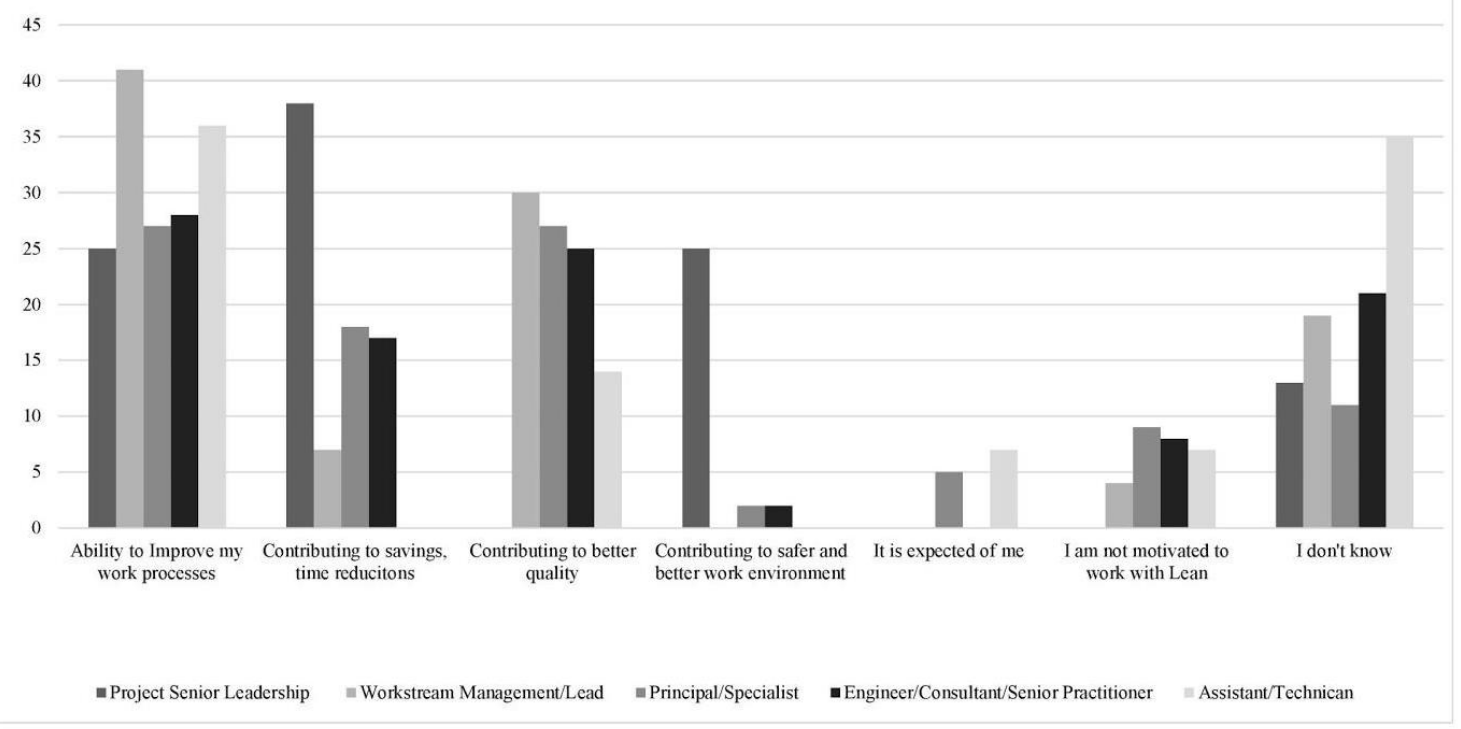

Figure 4: Responses to the question: What motivates you most to work with Lean? compared to role on project.

The senior management group are highly motivated by savings in time and cost, work stream leads are mostly motivated by improving own work processes, principals and specialists are mostly motivated by contributing to higher quality. Interestingly, the senior managers are the only group motivated by creating a safer and better work environment. Asking the opposite question on what demotivates the different groups the picture is more consistent, see figure 5 . 


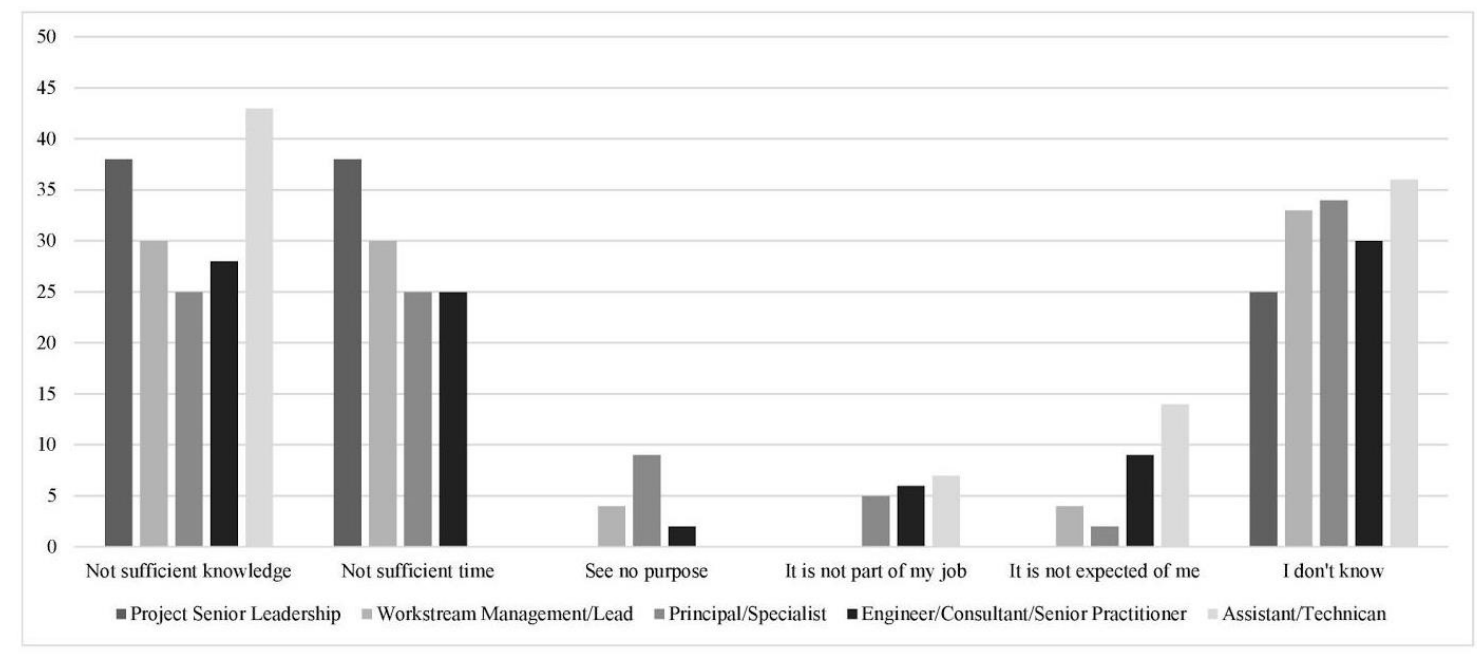

Figure 5: What demotivates you to work with Lean?

The demotivating factors across the team is that project team members do not feel they have enough time, knowledge or they do not know what demotivates them. Possibly also due to lack of knowledge of what lean entails.

\section{DISCUSSION: WHEN DOES IT MAKE SENSE TO CHANGE?}

The client, Highways England, in its strategy documents, tender and contractual requirements set out clear expectations towards the implementation of lean on the Lower Thames Crossing scheme. By setting clear expectations, Highways England has enabled lean implementation across the industry (Tezel, A. et al., 2016). The efficiency target and lean maturity assessment framework work as clear extrinsic motivation measures and enabled clear communication, with the project senior management team having bought into the need for lean implementation. This resulted in resourcing lean implementation from the early start of the project and appointing lean specialists to support the project team. In the survey the senior managers rated time and cost savings as the most motivating factor when working with lean. This is not surprising as this organisational level is measured on these parameters.

The results of lean assessments of the project organisations and on the project, itself indicates an increasing adoption of lean and an increasing use of lean on the Lower Thames Crossing scheme. In general, the project team members have a positive attitude towards Lean and support that it could be further developed within their role. $41 \%$ responded to have had some sort of Lean training and when asked to rate own knowledge the answers were also that they perceived they had some knowledge about lean. When asked about specific lean tools 53 have participated in Collaborative Planning and 45 in Choosing by Advantages. Despite this, the respondents pointed to lack of knowledge as one of the main barriers for engaging more in lean. 
Another main barrier for the project team to engage more in lean is a feeling of not having enough time. The perception on the project is also that there is a significant focus on schedule and cost savings. Looking back at the motivation theory, a strong focus on extrinsic motivation factors inhibit development of productivity in highly complex production settings (Pink, 2017).

Lean practitioners know that time constraints should not be a barrier to work with lean as applying lean techniques should free up resources. So, one answer to these barriers could therefore be to provide training and developing more evidence of lean. But this would be to do more or what we already have done, at it seems not to work.

Another answer could also be to ask whether the feeling for mastery is present with a project focus on cost and time savings. As seen in the literature, change require more than knowledge and will to change. When people do not immediately change behaviour despite knowledge of the benefits, it could be due to lack of bandwidth for change inhibiting system 2 to allow for deliberate changes. (Kahneman, 2011).

Al groups also point to the motivating factor of improving own work processes and for the engineers and specialists improving quality was also a motivation factor. These are intrinsic motivations of wanting to avoid inefficient working processes from own perspective. Many engineers and specialists are very proud of their own discipline and want to contribute to heighten the quality of the project instead of looking for savings in time and cost.

So perhaps what we see is a tension between the motivation of the senior managers that focus on time and cost savings while the rest of the organisation is motivated by solving problems and creating quality? And when managers then try to motivate by setting the scene with pressure on time and cost, this actually inhibit the rest of the organisation to change and invest in development?

Why is it that the lean managers have difficulties in convincing people to put an effort in to implementing lean even though it is acknowledged that it will be advantageous and a requirement of the client? One reason might be the organisation's strong focus on efficiency and production optimization, or what Ellström defines as the logic of performance (Ellström 2006). Refining and optimisation of existing procedures becomes the organisation's main objective. When lean managers enter the room, they bring a rationale, which at first glance does not correlate with the logic of performance. Implementing lean construction can remove time and resources from what are perceived as core activities. In order to overcome the gap between the project managers' focus on performance and the lean managers' interest in implementing lean construction, the lean managers construct best practice cases outlining the many possible positive gains in applying lean construction. Thereby, they try to create a fit in rationale between the business case and the logic the managers apply in their daily practice. Despite the convergence in rationale, managers do not implement lean construction - why is that so? Is it difficult to implement lean construction because it does not make sense to the managers? Continuously, the lean managers outline all the positive aspects in lean construction; however, these are the lean construction managers' understandings. Being told that lean construction is a good idea does not imply that it makes sense to the receiver of the message. The American social psychologist Karl Weick (1996) argues that implementation and change in behavior cannot 
be forced upon people; it is not possible to control organizations. What change agents can do is to provide alternative stories and cues and approach implementation of lean construction as sensemaking.

We are still stuck in a culture where we control and punish for unwanted or poor performance, and do not pay enough attention to what actually motivates people to deliver. Particularly, when it comes to work tasks that have no clear and precise outcome in the beginning, is this a fault. People need to think and solve problems, and design to deliver.

We would encourage future research to test the conclusion of this paper on more cases and to explore the benefit of addressing different motivating factors for different roles and disciplines.

\section{CONCLUSIONS}

Client organisations can, with explicit requirements in delivery strategies, tender and contract requirements, encourage suppliers to adopt a continuous improvement methodology such as lean. By setting explicit expectations the senior managers can be motivated to support and resource lean adoption. The managers are, to a large extent, measured on extrinsic measures such as time and cost, and thereby their motivation to support and work with lean also lies within these areas. Engineers and specialists see their purpose as improving quality and in general the most project team members were motivated by making own work processes better.

There was a disconnect between the respondent's ability to use lean and the actual experience they had within the field. The root cause for this could be the tension between motivation factors at the different organisation levels. A strong focus on time and cost could actually inhibit creative thinking and development of new processes. Senior managers and lean managers should be aware of this fact when developing lean implementation strategies. By focusing on what motivates the different roles in a project we might be able to better influence the adoption of a lean approach. So perhaps a business case is not enough to motivate our colleagues to work with lean.

\section{REFERENCES}

Bryman, A. (2015). Social Research Methods, 5th Revised Edition. Oxford University Press.

De Vaus, D. (2013). Surveys in Social Research, 6th Edition. Taylor \& Francis Ltd.

Drysdale, D. (2013). "Introducing lean improvement into the UK Highways Agency supply chain." In Proceedings of the 21th Annual Conference of the International Group for Lean Construction (IGLC), Fortaleza, Brazil.

Highways England. (2015). “Delivery Plan 2015-2020”. Leeds: Highways England Publications Team.

HM Government (2015b). "Road Investment Strategy: for the 2015/16 - 019/20 Road Period”. London: HM Stationery Office.

Howell, G.A. \& Koskela, L. 2000, 'Reforming Project Management: The Role of Lean Construction' In: 8th Annual Conference of the International Group for Lean Construction. Brigthon, UK, 17-19 Jul 2000. 
Ellström, P.E. (2006). Two Logics of Learning. In: Antonacopoulou, A. et al. Learning, Working and Living. Mapping the Terrain of Working Life Learning. Palgrave Macmillan

Kahneman, D. (2011). "Thinking, Fast and Slow”. Penguin Books.

Korb, S. \& Ballard, H.G. (2018), 'Believing Is Seeing: Paradigms as a Focal Point in the Lean Discourse' In: 26th Annual Conference of the International Group for Lean Construction. Chennai, India, 18-20 Jul 2018. pp 177-186

Koskela, L. , Ballard, G. \& Howell, G. 2003, 'Achieving Change in Construction' In:, 11th Annual Conference of the International Group for Lean Construction. Virginia, USA, 1 -.

Münster, M. (2017). “Jytte fra Marketing er desværre gået for i dag, Sådan bruger du adfærdsdesign til at skabe forandringer i den virkelige verden (How to use behavioural design to create changes in the real world. In Danish). ISBN 0799702243581, Gyldendal A/S

Pink, D. H.. (2007). "Drive. The surprising truth about what motivates us". Canongate Books. ISBN 9781847677693.

Ryan, R.M. and Deci, E. L. (2000). Intrinsic and Extrinsic Motivations: Classic Definitions and New Directions. Contemporary Educational Psychology 25, 54-67

Schöttle, A., Arroyo, P., Christensen R. (2018). "Demonstrating the value of an effective collaborative decision-making process in the design phase." 26th Annual Conference of the International. Group for Lean Construction, Chennai, India, 18-20 Jul 2018

Tezel, A. Aziz, Z., Koskela,.L., Tzortzopoulos, P. (2016). "Visual Management Condition in Highways Construction Projects in England" 24th Ann. Conf. of the Int'l. Group for Lean Construction, Boston, MA, USA, sect.6 pp. 133-142. Available at: .

Weick, K.E. (1995). Sensemaking in Organizations. Sage Publications Inc. 
Christensen, R., Greenhalgh, S., and Thomassen, A.

Proceedings IGLC - 27, July 2019, Dublin, Ireland 